\title{
Maternal Exposure to Bisphenol A Impacts on Fecundity in F1 and F2 Generations in Drosophila melanogaster
}

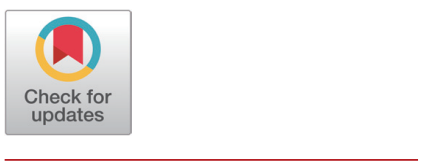

* These authors contributed equally to this work.

Received: May 12, 2021

Revised: July 20, 2021

Accepted: August 16, 2021

\section{${ }^{\dagger}$ Corresponding author} Hyongjong Koh

Department of Pharmacology, Dong-A University College of Medicine, Busan 49201, Korea.

Tel: +82-51-240-2805

E-mail:hjkoh@dau.ac.kr

Copyright $\odot 2021$ The Korean Society of Developmental Biology.

This is an Open Access article distributed under the terms of the Creative Commons Attribution Non-Commercial License (http://creativecommons.org/licenses/ by-nc/4.0/) which permits unrestricted non-commercial use, distribution, and reproduction in any medium, provided the original work is properly cited.

ORCID

Sohee Kim

https://orcid.org/0000-0002-7457-4029

Kyong-hwa Kang

https://orcid.org/0000-0003-3124-2988

Hyongjong Koh

https://orcid.org/0000-0003-2594-4799

Conflict of interests

The authors declare no potential conflict

of interest.

Acknowledgements

This work was supported by grants from the National Research

Foundation of Korea, funded by the

Ministry of Science and ICT (Grant No.:

2020R1F1A105165912).

Authors' contributions

Conceptualization: Koh $\mathrm{H}$.

Data curation: Kim S, Kang K.

Formal analysis: Kim S, Kang K.

Methodology: Kim S, Kang K.

Investigation: Kim S, Kang K.

\author{
Sohee Kim ${ }^{*}$, Kyong-hwa Kang ${ }^{*}$, and ${ }^{\dagger}$ Hyongjong Koh \\ Department of Pharmacology, Dong-A University College of Medicine, Busan 49201, Korea
}

\begin{abstract}
In previous reports, bisphenol A (BPA) exposure affects reproductive function in Drosophila melanogaster females. To test the maternal effect of BPA exposure on fly reproductive function, F0 mothers were exposed to $0,0.1,1$, and $10 \mathrm{mg} / \mathrm{L}$ of BPA and the fecundity in $\mathrm{F} 1$ and $\mathrm{F} 2$ generations were checked. In this experiment, 1 and $10 \mathrm{mg} / \mathrm{L}$ BPA significantly decreased the fecundity of $\mathrm{F} 1$ females. Moreover, 0.1 and $1 \mathrm{mg} / \mathrm{L}$ BPA substantially reduced egg production in the F2 generation. These results suggested that maternal exposure to BPA at enviromentally relavant concnetrations reduces reproductive function in Drosophila melanogaster females and that this effect is transgenerational.
\end{abstract}

Keywords: Bisphenol A, Drosophila melanogaster, Fecundity, Transgenerational

\section{INTRODUCTION}

Bisphenol A (BPA) is a chemical monomer used world-wide in the manufacture of polycarbonate plastics and epoxy resins and found in many products such as food and drink containers, toys, thermal paper, dental sealants, medical devices, flame retardant materials and so on (Michałowicz, 2014). As a result, humans have been constantly exposed to BPA through dietary and non-dietary sources. BPA and its metabolites are found in the majority of human body fluids including blood and urine. In analysis by the CDC BPA is present in $92.6 \%$ of human urine samples (Calafat et al., 2008). Moreover, BPA is also found in human ovarian follicular fluid, placental tissue, and fetal serum (Ikezuki et al., 2002; Schönfelder et al., 2002). The presence of BPA in maternal reproductive tissues and fluids indicates that BPA exposure can occur at developmental stages and thus, it has potential to affect subsequent generations through the germ line.

Several studies have examined the effects of embryonic BPA exposure on reproductive outcomes using rodent models. Perinatal exposure to BPA induced a decline in fertility and fecundity in the F1 generation of CD-1 mice (Cabaton et al., 2011). Further, in utero exposure to BPA disrupts ovarian development and estrous cycle in the F1 generation of FVB mice (Wang et al., 2014). In the same study, the BPA exposure also significantly reduced fertility in the F1 females (Wang et al., 2014). Moreover, in utero BPA exposure can compromise some female fertility phenotypes in the F2 and F3 generations suggesting that some effects may be transgenerational (Ziv-Gal et al., 2015).

In this report, the maternal effects of BPA on the fecundity in F1 and F2 generations were examined using Drosophila melanogaster. Drosophila melanogaster, due to its short lifespan and well-defined 
Writing-original draft: $\mathrm{Koh} \mathrm{H}$. Writing-review \& editing: Koh $\mathrm{H}$.

Ethics approval

This article does not require IRB/IACUC approval because there are no human and animal participants. genetics, offers many advantages for the detection of mutagenic, morphological and developmental effect of chemical agents over generations. Exposure to environmentally relevant concentrations of BPA significantly decreased the fecundity of F1 and F2 female flies, showing maternal and transgenerational effects of BPA on Drosophila melanogaster reproductive function.

\section{MATERIALS AND METHODS}

In this study, the wild type $w^{1118}$ fly was used. The flies were kept in a Drosophila culture room at $25^{\circ} \mathrm{C}$ and relative humidity of 50\%-60\% and in $12 \mathrm{~h}$ light, $12 \mathrm{~h}$ dark periods on a standard cornmeal Drosophila medium. Virgin female flies (2-3 day old) were exposed to 0, 0.1, 1, and 10 $\mathrm{mg} / \mathrm{L} \mathrm{BPA}$ in the standard medium. After 24 hours, the exposed 20 females and non-exposed 10 males of same age (3-4 day old) were crossed in the standard medium without BPA. 10 days later, $\mathrm{F} 1$ virgin females were collected and incubated in the standard medium. After 3 days, $20 \mathrm{~F} 1$ virgin females were crossed with 10 unexposed males of same age (3-day-old) in the grape juice agar plates. These plates were changed for every $24 \mathrm{~h}$ and the eggs were counted for a period of 3 days. After counting, the eggs were reared on the standard medium and F2 virgin females were collected. Twenty 3-day-old F2 virgin females were crossed with 10 unexposed males of same age and their eggs were counted in the same way as the eggs laid by the F1 females were counted. The results were expressed as percentages relative to controls (F1 or F2 females generated using F0 females exposed to $0 \mathrm{mg} / \mathrm{L} \mathrm{BPA}$ ). To compare control and test groups, we used a one-way ANOVA with Sidak correction. The statistical analysis of the results was carried out using the Prism program.

\section{RESULTS AND DISCUSSION}

In previous studies, Vimal et al. reported that BPA exposed female flies have smaller ovaries with fewer mature oocytes and abnormal ovarian follicles (Vimal et al., 2019). The fecundity of these exposed females is also reduced and their eggs are defective in maternal transcripts and proteins (Vimal et al., 2019). The negative effect of BPA on female fertility was also observed in another Drosophila melanogaster study (Atli, 2013). To test the maternal effect of BPA exposure on fly reproductive function, we exposed Drosophila melanogaster females to environmetally relavant concentrations $(0,0.1,1$, and $10 \mathrm{mg} / \mathrm{L})$ of BPA and crossed with non-exposed males on the standard fly food without BPA. The F1 generations were reared on the same fly food and their fecundity was checked (Fig. 1). Although $0.1 \mathrm{mg} / \mathrm{L}$ BPA had no effect on F1 fly fecundity, $1 \mathrm{mg} /$ L BPA significantly reduced the fecundity compared to controls. Moreover, $10 \mathrm{mg} / \mathrm{L}$ BPA further decreased the fecundity of F1 females showing that the effect of BPA on female fecundity in the F1 generation is dose dependent. These data demonstrated that maternal exposure to BPA decreases female reproductive function in Drosophila melanogaster.

To test whether the effect of BPA on the fly fecundity is carried over next generation, we generated F2 females using the F1 females. Surprisingly, when F0 grandmothers were exposed to $0.1 \mathrm{mg} / \mathrm{L}$ and $1 \mathrm{mg} / \mathrm{L} \mathrm{BPA}$, the egg production of their $\mathrm{F} 2$ granddaughters was significantly decreased (Fig. 2). In contrast, $10 \mathrm{mg} / \mathrm{L} \mathrm{BPA} \mathrm{exposure} \mathrm{had} \mathrm{no} \mathrm{effect} \mathrm{on} \mathrm{the} \mathrm{fecundity} \mathrm{in} \mathrm{the} \mathrm{F2}$ generation (Fig. 2), showing that environmentally more relevant concentration $(0.1 \mathrm{mg} / \mathrm{L}$ and 1 $\mathrm{mg} / \mathrm{L}$ ) of BPA can reduce the fly fecundity over generations. Interestingly, Ziv-Gal et al. reported that lower concentration of BPA can induce more profound decline in fertility of female mice over generations (Ziv-Gal et al., 2015). Moreover, Alworth and colleagues demonstrated that in utero 


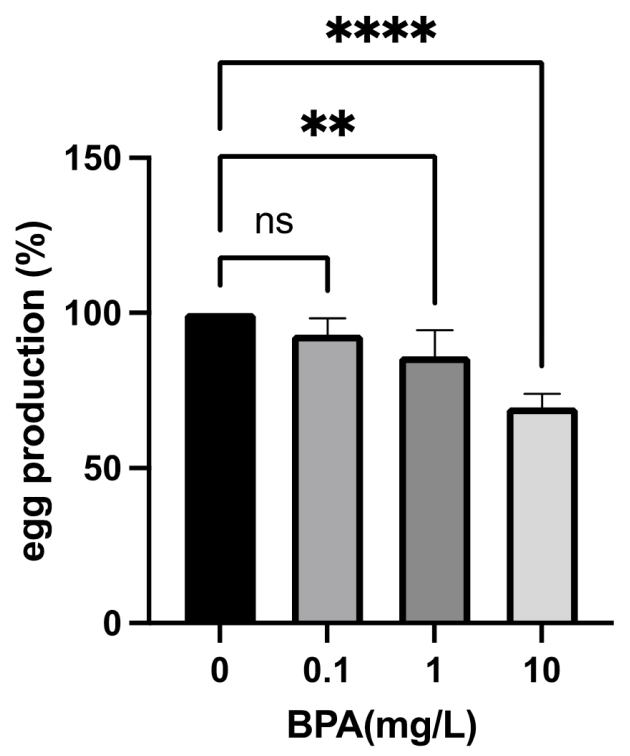

Fig. 1. The effect of maternal BPA exposure on female fecundity in the F1 generation. The egg production in the F1 generation were expressed as percentages relative to the unexposed control $(0 \mathrm{mg} / \mathrm{L})$. The average egg production was obtained from five independent experiments and significance was determined by one-way ANOVA with Sidak correction. ${ }^{* \star} p<0.01$; ${ }^{* \star *} p<0.0001$; Error bars indicate SD. ns, not significant; BPA, bisphenol A.

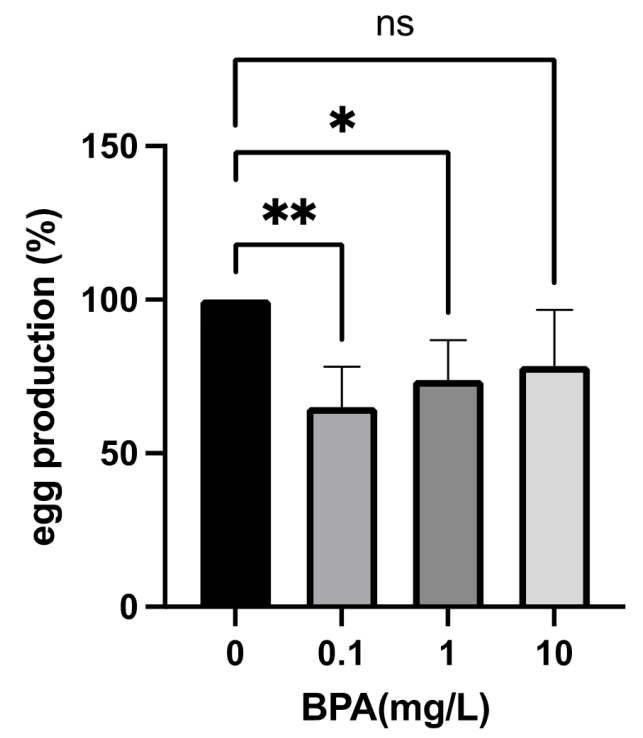

Fig. 2. The effect of maternal BPA exposure on female fecundity in the F2 generation. The egg production in the F2 generation was expressed as percentages relative to the unexposed control $(0 \mathrm{mg} / \mathrm{L})$. The average egg production was obtained from four independent experiments and significance was determined by one-way ANOVA with Sidak correction. ${ }^{*} p<0.05$; ${ }^{* *} p<0.01$; Error bars indicate SD. ns, not significant; BPA, bisphenol A.

exposure of CD-1 mice to diethylstilbestrol (DES), another endocrine disrupting chemical (EDC), caused opposite responses between low and high doses (Alworth et al., 2002). Under administration of estradiol, the low dose $(0.1 \mu \mathrm{g} / \mathrm{kg})$ of DES increased uterine weight, while the high dose (100 $\mu \mathrm{g} / \mathrm{kg}$ ) significantly reduced uterine weight compared to controls (Alworth et al., 2002). These 
data indicate that the high dose of BPA directly affects egg production in the F1 generation, while the lower dose of BPA reduces female reproductive function in the next generations by inducing long lasting changes such as epigenetic modifications. Therefore, the epigenetic alterations in BPA exposed female flies and their offspring across dose (from 0.1 to $10 \mathrm{mg} / \mathrm{L}$ ) will be our next topic.

The transgenerational effects of EDCs on female reproduction in mice and rats have been reported by various research groups (Manikkam et al., 2013; Bruner-Tran et al., 2016; Zhou et al., 2017; Rattan et al., 2018). However, the rodent models have some limitations such as relatively long generation time and difficulties in genetic manipulation. As Drosophila melanogaster has many advantages such as short generation time (10-12 days) and powerful genetics, our fly model can be useful to study transgenerational effect of BPA and other EDCs to female fertility.

\section{REFERENCES}

Alworth LC, Howdeshell KL, Ruhlen RL, Day JK, Lubahn DB, Huang TH, Besch-Williford CL, vom Saal FS (2002) Uterine responsiveness to estradiol and DNA methylation are altered by fetal exposure to diethylstilbestrol and methoxychlor in CD-1 mice: Effects of low versus high doses. Toxicol Appl Pharmacol 183:10-22.

Atli E (2013) The effects of three selected endocrine disrupting chemicals on the fecundity of fruit fly, Drosophila melanogaster. Bull Environ Contam Toxicol 91:433-437.

Bruner-Tran KL, Duleba AJ, Taylor HS, Osteen KG (2016) Developmental toxicant exposure Is associated with transgenerational adenomyosis in a murine model. Biol Reprod 95:73.

Cabaton NJ, Wadia PR, Rubin BS, Zalko D, Schaeberle CM, Askenase MH, Gadbois JL, Tharp AP, Whitt GS, Sonnenschein C, Soto AM. (2011) Perinatal exposure to environmentally relevant levels of bisphenol A decreases fertility and fecundity in CD-1 mice. Environ Health Perspect 119:547-552.

Calafat AM, Ye X, Wong LY, Reidy JA, Needham LL (2008) Exposure of the U.S. population to bisphenol A and 4-tertiary-octylphenol: 2003-2004. Environ Health Perspect 116:39-44.

Ikezuki Y, Tsutsumi O, Takai Y, Kamei Y, Taketani Y (2002) Determination of bisphenol A concentrations in human biological fluids reveals significant early prenatal exposure. Hum Reprod 17:2839-2841.

Manikkam M, Tracey R, Guerrero-Bosagna C, Skinner MK (2013) Plastics derived endocrine disruptors (BPA, DEHP and DBP) induce epigenetic transgenerational inheritance of obesity, reproductive disease and sperm epimutations. PLOS ONE 8:e55387.

Michałowicz J (2014) Bisphenol A: Sources, toxicity and biotransformation. Environ Toxicol Pharmacol 37:738-758.

Rattan S, Brehm E, Gao L, Flaws JA (2018) Di(2-Ethylhexyl) phthalate exposure during prenatal development causes adverse transgenerational effects on female fertility in mice. Toxicol Sci 163:420-429.

Schönfelder G, Wittfoht W, Hopp H, Talsness CE, Paul M, Chahoud I (2002) Parent bisphenol A accumulation in the human maternal-fetal-placental unit. Environ Health Perspect 110:A703-A 707.

Vimal D, Saini S, Kristipati RR, Chowdhuri DK (2019) Atrazine or bisphenol A mediated negative modulation of mismatch repair gene, mlh1 leads to defective oogenesis and reduced female fertility in Drosophila melanogaster. Chemosphere 225:247-258.

Wang W, Hafner KS, Flaws JA (2014) In utero bisphenol A exposure disrupts germ cell nest breakdown and reduces fertility with age in the mouse. Toxicol Appl Pharmacol 276:157-164. 
Zhou C, Gao L, Flaws JA (2017) Exposure to an environmentally relevant phthalate mixture causes transgenerational effects on female reproduction in mice. Endocrinology 158:1739-1754.

Ziv-Gal A, Wang W, Zhou C, Flaws JA (2015) The effects of in utero bisphenol A exposure on reproductive capacity in several generations of mice. Toxicol Appl Pharmacol 284:354-362. 
